\title{
Marxist Friend on the Role of the Scientist in the Modern Times
}

\section{Thanasis Argiriou*}

Physicist and Independent Researcher, Thessaloniki, Greece

\section{Keywords: Marxist; Scientist; Modern times}

Was discussing with a Marxist friend on the role of the scientist in the modern times. His approach was that the scientist should leave the specific-specialist and become more socially involved, and be able to provoke the crowds to any revolutionary holistic views that involve nature and society. My friend thinks that scientists on the edge should get involved with society rather at being in their labs, and lead society giving steadily their edge knowledge to the public, and being an active part on society.

Since I am writing about Marx, following this line is that we are nearing the end of Capitalism, and the crisis are the tides of an ending period.

I do not know if my Marxist friend is correct, and the edgy scientists at the forefront of knowledge should be in a big list called edge science, have seminars, built universities, have their own funding, maybe we are afraid that being on the edge and neglected has become usual to us, and we are hiding in our caverns.

Personally, I do not know of many people going into experiments to changing the way they perceive the world, and very few who would want to change the life they live and going into exploration. So I do not engage in trying to change any, cause change means an alteration other than the theory to the ego and to the neurophysiology. A good conversation is welcome but at the end of it, I understand that conversing might be a form of communications problematic at its core.

Since in nature, in applicative science, and in art are billions of differentiations I wonder where is the holistic approach of science and where is the advance in society and in humanity as individual species. As I understand this a radical empiricism in scientific theory should lead to a radical change in the way we think but also to our relationships with each other and last to the way we see ourselves complementary to the world.

Semiosis fronts into the consideration of dialogue, whereas the system of semiosis is inconsistent, in order for a dialogue to be reached, and from the dialogue a steady point reached as a result or a structure. A dialogue is a dynamics already built in and arises from a structure already held. For a corresponding dialogue to be held, a further stability new point should be reached, from which a different dialogical built can be held, in an alternate semiosis, to reach again to a new point, from which another semiosis would originate, and so forth.

The problem of instability in the dialogue's results, surmounts to that the dialogue is not successful, so the older semiosis can not be replaced by a next.

Comparing this with society at current rate, is that previous societal semiosis remains the same or even worsens, while technological semiosis extends, thus technology advances while society deteriorates. Nationalism, muslims, and changes in working rights and culture, offer society losing grade, and only in the environment protection gaining height-greenhouse affect,wildlife protection, alternate energy, waste management, pets, self sufficiency. So the viewpoint is similar to an election result, there is nothing ideologically new. and the positive effects are only leftovers of the ideological waste land reverting into small semi processed clean pools.
From the epistemological point of view, science and new modern discovery, never met their ends meets. Modern physics, psychology, and dynamics, instead of pushing the hilt

further inside into internal semiosis existentialism and ethics, and external democracy, were rather obfuscated into technological advancement and metaphysical under treatment. This not only lead to a more separated and uninvolved society but also to a false libertarianism, and a surfacial ego centered culture, even living science out of the picture, and scientists becoming specialists and uninvolved in the search of knowledge and truth or uinvolved to society. Thus saying that though modern science of the 20th century made the drill, the following generations made the oil spills, the drill was not meant to be used for finding oil, it was a tool unknown that we should learn what it was and how to use it, giving an equal and more struggle to the efforts of the previous.

So it goes for literature and the general term named art. A dynamical structure that fails to advance, will in the end dissolve in order to form a new more stable form, that is in speed with the currents flow, and so it goes, otherwise catastrophy occurs, at the beginning partially to reach at a point a critical climax, thus to begin again a new order of structures. The world is in constant feedback, we can go back from what the previous scientists reported and find out, it is now history and also truth, we can not hide our heads in the media, or in technology, or fantasy, and from a point on can never return, what is done is done and everyone has to face the consequences.

Since in dynamics, an emergence of an attractor in higher or lower dimensions, depends where we put the consequence in the later, or the previous. If the dimension say we put energy into a more physical space, is in higher energy, this means the work and the patterns followed would come from the higher energy spectrum.

If we view the dynamics holistically, then the bonds between the system would recreate the emergence, of patterns and forms. So saying that the system always behaves like a holon, and every observation we make is non-other than the holons function, that resoonds through us. Time is nothing other than space in observation, observation sequences, consider the medium used to observe which are bonds of they system, as vectors that define the observations which is none other than the observer and therefor a differential of the holon, in local-topos.

This sequence of time, gives of our incidents accidents relationships creations discoveries, in the vector field topos bonds. Patterns help us

*Corresponding author: Thanasis Argiriou, Physicist and Independent Researcher, Thessaloniki, Greece, Tel: +30 6957316558; E-mail: argyrioy@gmail. com

Received July 15, 2015; Accepted February 22, 2016; Published February 29 2016

Citation: Argiriou T (2016) Marxist Friend on the Role of the Scientist in the Modern Times. J Psychiatry 19: 353 doi:10.4172/2378-5756.1000353

Copyright: (C) 2016 Argiriou T. This is an open-access article distributed under the terms of the Creative Commons Attribution License, which permits unrestricted use, distribution, and reproduction in any medium, provided the original author and source are credited 
distinguish, but the patterns potential in understanding is too statistically scarce to reach, so pattern theory as means towards understanding and evolving, is only a guess at present, since our learning as humans in education is based in other more primitive ways, were observation is made in single distinctions.

Every action and thought is recorded in the world, thus when an observation is chosen- would not say choice exactly but rather dynamics of each distribution of the holon- this recreates the next path, and this the next, and this the next, and the next and the next and the next. The holon is always there it just manifests in differentials for each different smaller representation of it.

Though so, the holon is a never ending scale, each as individual, is just a tiny differential, and as humans we appear as a cell appears to our human potential- no, it is something we can not analog, and completely unknown to any intelligence, human or not.

If you ask the air and it does not respond to you, then that does not mean that the air can not respond, it means that the air does not respond to what you ask. The air responds to its own meaning, and if both your meanings and that of the air intersect, then you will get a reply of the air, and of this reply, you will get a consonant of the airs meanings, and an infenitesimal part of its essense. Most of science is intersection of meanings, and creation of substances, in the interaction of meanings and retrocausal significanses.

This end of psychology, is not of the failure of psychology, but of the failure of people to find meaning in psychology, and therefor its meaning gets replaced by neuroscience and molecular biology, further more it is the failure of modern man, as seen in Jung's unsettling quote modern man in search of his soul. Psychology is not an easy field, it is a basic field from which math and language emerge, as symbols and signs, and from which physics which is the relation of psychology logical constucts surge. Thus psychology is a vastly uncharted area, much more difficult to venture than even physics is, pertaining the nature of the world and the history of the world.

From end and beginning of study into results such as oscillations and archetypes, essenses concerning substances that we meet, we tend to evaluate from the semiosis, and from those using the operants of semiosis, become other operants secluding the powerful undercurrents from which semiosis rises, and end up caught in the tidal waves we ourselves create. Thus psychology is primitive in form, and little charted, for if a person can truly access psychology then he or her would have access to the mysteries and the forces of nature, and also to natures early appearances, which as early, are also primal and appeal to the formost creztional and destructive parts of itself, and of the essense of each individual.

The mirror reflects this image, and this image is of those who created the mirror, and those who see the mirror, reflect only part of their reflection and the reflection of the mirror, but most of the image is not reflected back. Being part of the holon I understand that my position is just a place in the set, and it will always be so. Each moment will always be infinitesimal and thus infinite, and also distinct and unique from any other moment. No moment can be replaced of repeated by any man or God, as this would detail another creation of another moment.

The world ever moves, in its own strange holistic roads, and I guess for us humans it is finding the rleationship of the holon in ourselves and in the holon to move on, and live in much happier grounds and fields. As Plato describes man should in the discovery of beauty move on to become, and this beauty is internal, as each moment, never repeats its self. The rules of destruction and creation are in the basis of psychology and physics, oscillation is constant.

Best wishes to the people of the magazine and to the readers, hope that in the years to come the articles would be more social, psychological, and nature inclined. 